\title{
Student Perception of "A" Fighting Workshop for Digital Information Technology (Digital Technology) Program PSMZA
}

\author{
Norhafiza Binti Idris ${ }^{1 *}$, Noor Rulhanim Binti Mohamad Ariffin ${ }^{2}$ \\ ${ }^{12}$ Politeknik Sultan Mizan Zainal Abidin \\ $ఏ$ e-mail: norhafiza@psmza.edu.my
}

\begin{abstract}
Programme of study Diploma in Information Technology (DDT) provides education and training in the field of computing with specific emphasis on the areas of Information Technology. In order to ensure technology development in line with the needs of industry, Department of Polytechnic Education (JPP) have checked the curriculum Diploma of Information Technology (Digital Technology). Curriculum Diploma of Information Technology (Digital Technology) has set a $40 \%$ as a pass score for Discrete Mathematics course (DBM2033) in the assessment of coursework and final examination. However, students who take courses in Discrete Mathematics (DBM2033) is weak in terms of calculation and this resulted in their results less impressive in this course. This continuity, a Bengkel Gempur "A" for the Diploma of Information Technology (Digital Technology) was implemented. This research in the form of surveys and applying data obtained from the questionnaire. The samples consist of 54 semester two students who take courses in Discrete Mathematics (DBM2033) for session June 2017. Pilot study of reliability value $\alpha=0.930$. The findings of this study show the level of students ' perception of Bengkel Gempur " $A$ " are at a high level and students have a positive perception after following the workshop. However, the findings show there is no difference in perception among the students based on the demographics of the respondents, i.e. gender, race, age, education status and cumulative grade points average (CGPA). Students ' perception on the Bengkel Gempur " $A$ " has changed since joining the program. This has proved through score mean before the programme was 2.28 and mean score after participating in the programme was 2.96 which increased by 0.68 . This study demonstrated that the implementation of Bengkel Gempur " $A$ " has managed to increase the level of student achievement onfinal examination sessions June 2017.
\end{abstract}

Keywords:perception; students; Bengkel Gempur "A”; Mathematics

\section{Persepsi Pelajar terhadap Bengkel Gempur "A"bagi Program Diploma Teknologi Maklumat (Teknologi Digital) PSMZA}

\begin{abstract}
Program pengajian Diploma Teknologi Maklumat (DDT) menyediakan pendidikan dan latihan dalam bidang pengkomputeran dengan penekanan khusus pada bidang Teknologi Maklumat. Untuk memastikan pembangunan teknologi selaras dengan keperluan industri, Jabatan Pendidikan Politeknik (JPP) telah menyemak kurikulum Diploma Teknologi Maklumat (Teknologi Digital). Diploma Kurikulum Teknologi Maklumat (Teknologi Digital) telah menetapkan 40\% sebagai mata pelajaran lulus untuk kursus Matematik Diskret (DBM2033) dalam penilaian kursus dan peperiksaan akhir. Walau bagaimanapun, pelajar yang mengambil kursus dalam Matematik
\end{abstract}


Diskret (DBM2033) adalah lemah dari segi pengiraan dan ini menyebabkan keputusan mereka kurang menarik dalam kursus ini. Kesinambungan ini, Bengkel Gempur "A" untuk Diploma Teknologi Maklumat (Teknologi Digital) telah dilaksanakan. Kajian ini dalam bentuk tinjauan dan data yang diperoleh dari soal selidik. Sampel terdiri daripada 54 semester dua pelajar yang mengambil kursus dalam Matematik Diskrit (DBM2033) untuk sesi Jun 2017. Kajian percubaan nilai kebolehpercayaan $\alpha=0.930$. Penemuan kajian ini menunjukkan tahap persepsi pelajar terhadap Bengkel Gempur "A" berada di tahap yang tinggi dan pelajar mempunyai persepsi positif setelah mengikuti bengkel tersebut. Walau bagaimanapun, penemuan menunjukkan tiada perbezaan persepsi di kalangan pelajar berdasarkan demografi responden, iaitu jantina, bangsa, umur, status pendidikan dan purata mata gred kumulatif (CGPA). Persepsi pelajar terhadap Bengkel Gempur "A" telah berubah sejak menyertai program ini. Ini telah terbukti melalui skor min sebelum program itu adalah 2.28 dan skor min selepas menyertai program ini ialah 2.96 yang meningkat sebanyak 0.68. Kajian ini menunjukkan bahawa pelaksanaan Bengkel Gempur " $A$ " telah berjaya meningkatkan tahap pencapaian pelajar pada sesi ujian pada Jun 2017.

Keywords:perception; students; Bengkel Gempur “A”; Mathematics

\section{PENGENALAN}

Amalan Pelancaran pelan baru iaitu Pelan Pembangunan Pendidikan Malaysia 2015-2025 (Pendidikan Tinggi) telah mengubah dan melakar sejarah penting dalam sistem pendidikan Malaysia. Ia terhasil kesan daripada kesedaran terhadap sumbangan besar pendidikan tinggi dalam membantu negara mencapai aspirasi sebagai negara berpendapatan tinggi. Terdapat sepuluh lonjakan utama yang harus dicapai Institusi Pendidikan Tinggi (IPT) awam dan swasta serta Pendidikan Aliran Teknikal dan Vokasional atau TVET(Mohammad \& Mohd Roslan, 2017).Melalui pelan transformasi ini juga, turut ditekankan adalah penguasaan pengetahuan mata pelajaran teras seperti sains dan matematik. Matematik merupakan satu kemahiran yang penting dan perlu digunapakai dalam bidang pekerjaan, khususnya berkaitan kejuruteraan, teknologi maklumat, perniagaan dan perakaunan. Justeru itu, bakal graduan lepasan institusi pengajian tinggi amat dititikberatkan dengan pengetahuan matematik. Bahkankemahiran matematik juga perlu dikuasai oleh graduan aliran TVET.

Matematik membawa makna yang berbeza bagi setiap individu. Kebanyakkan pelajar merasakan matematik sebagai satu mata pelajaran yang telah ada dalam buku teks dan ia tidak mempunyai kaitan dengan kehidupan seharian mereka. Persepsi dan sikap pelajar terhadap pembelajaran matematik sepanjang hayat telah mendorong Rengga \& Dalla (1992) untuk membuat kajian awal bagi mendapatkan peringkat pemerolehan kemahiran matematik terhadap pelajar berkenaan.Persepsi pelajar juga tidak hanya berdasarkan kepada persekitaran pembelajaran yang sebenar semata-mata, tetapi juga bergantung kepada pengalaman pembelajaran terdahulu dan terkini dan ini sokong oleh dapatan kajian(Abu Bakar \& Ismail, 2011).

\section{Latar Belakang Kajian}

Jabatan Matematik, Sains dan Komputer (JMSK) merupakan jabatan sokongan akademik yang menyediakan platform kepada proses pembelajaran dan pengajaran bagi kursus Kod DBM iaitu matematik yang menjadi kursus teras kepada pelajar teknologi maklumat. JMSK tidak menawarkan sebarang program tetapi mengendalikan kursus teras bagi Jabatan Teknologi Maklumat dan Komunikasi (JTMK). JMSK juga sentiasa menyokong perjalanan pembelajaran dan pengajaran di jabatan induk dengan menghulurkan sumbangan sebagai tenaga pengajar dan penyelaras kursus ko-kurikulum.

Dalam kajian ini, penyelidik telah mengadaptasi kerangka konseptual hasil daripada dapatan kajianGardiner (1989) iaitu melalui Model Konseptual Perubahan Sistematikseperti yang digambarkan dalam Rajah 1.Persepsi pelajar merupakan pembolehubah bebas yang dihubungkait dengan keberkesanan pelaksanaan bengkel matematik iaitu Bengkel Gempur "A". Hasil kajian ini akan dapat memperlihatkan 
persepsi pelajar terhadap Bengkel Gempur "A" bagi Program Diploma Teknologi Maklumat (Teknologi Digital) di PSMZA.

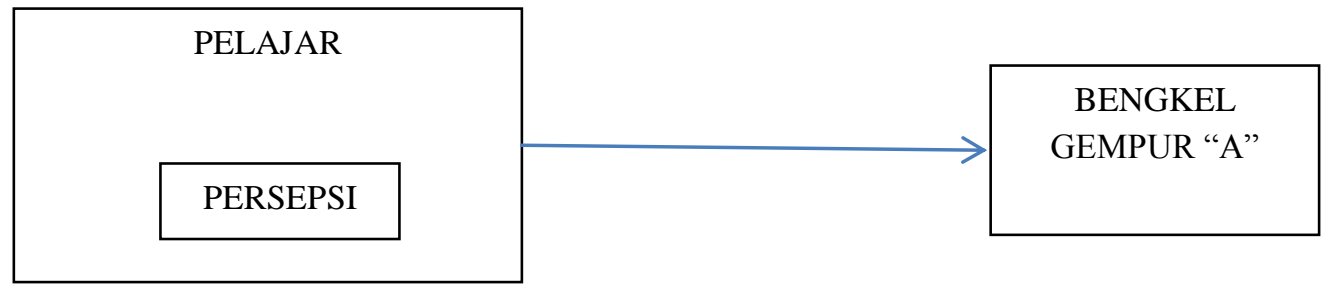

Rajah 1 : Kerangka Konseptual Kajian

\section{Pernyataan Masalah}

Bagi sesetengah pelajar sekolah mahupun di IPT, masih wujud stigma bahawa matematik adalah satu subjek yang sukar untuk difahami dan dikuasai (Norziah et. al, 2014).Sehubungan dengan itu, pelajar cuba mengelak untuk memilih kerjaya yang berkaitan dengan matematik atau mengambil kursus matematik di peringkat lebih tinggi.Sebagaimana yang dilaporkan oleh Scarpello (2007), hampir 75 peratus rakyat Amerika Syarikat menolak kerjaya yang berkaitan dengan matematik. Ramai graduan yang memasuki pasaran kerja gagal untuk mengaplikasikan pengetahuan matematik dalam kerjaya mereka. Hal ini disebabkan oleh mereka tidak dapat menguasai kursus matematik sepenuhnya semasa di peringkat sekolah ataupun IPT dan ini menjejaskan gred peperiksaan akhir mereka.Malah ada yang beranggapan bidang pekerjaan tidak memerlukan kemahiran matematik yang tinggi berbanding kemahiran kerja yang lain.Walaubagaimanapun, persepsi dan sikap sebegini haruslah dielakkan bagi memastikan kemajuan negara dapat ditingkatkan. Ini adalah berdasarkan kepada dapatan Zeynivandnezhad et. al (2012) yang menyatakan bahawa, matematik adalah satu kemahiran asas yang sangat penting bagi sesuatu komuniti.Bagi menguasai bidang teknikal, ia memerlukan penguasan matematik yang baikdan lebih meluas. Matematik sememangnya satu subjek yang cukup sinonim dan sering digunakan serta memerlukan graduan mengusainya dengan mendalam. Ini turut disokong oleh dapatan Mohammad \& Mohd Roslan (2017) iaitu graduan yang memasuki pasaran kerja seharusnya sedar akan kepentingan matematik serta dapat mengaplikasikan pengetahuan matematik dalam kerjaya mereka.

Di Politeknik Sultan Mizan Zainal Abidin (PSMZA), pelajar jurusan komputer iaitu dari Jabatan Teknologi Maklumat dan Komunikasi (JTMK) wajib mengambil subjek matematik dalam pengajian mereka. Terdapat dua kursus matematik yang ditawarkan kepada pelajar JTMK iaitu DBM1033(Mathematical Computing) pada semester satu dan DBM2033 (Discrete Mathematics) pada semester kedua.Kursus DBM2033 merupakan kursus wajib diambil bagi pelajar politeknik yang mengikuti Diploma Teknologi Maklumat(Teknologi Digital). Kursus DBM2033 telah menggantikan kod lama DBM2023 (Discrete Mathematics) dengan beberapa perubahan silibus yang lebih baik. Merujuk silibus kurikulum Jabatan Pengajian Politeknik (JPP), assessment bagi DBM2033 dibahagikan kepada dua bahagian iaitu Coursework Assessment (CA)dan Final Examination Assessment (FE). Markah lulus bagi Coursework Assessment(CA) adalah 40\% dan jika pelajar tersebut lulusCoursework Assessment(CA) barulah pelajar tersebut layak menduduki peperiksaan akhir. Markah lulus untuk peperiksaan akhir bagi kursus ini juga adalah $40 \%$.

Namun begitu, rumusan dari Course Review Report (CORR) keputusan peperiksaan akhir sesi Dis 2016 di PSMZA mendapati pencapaian pelajar dalam DBM2033 adalah sederhana iaitu sekitar61\%. Kesinambungan dari itu, satuinisiatif telah diambil oleh pihak JMSK dengan mengadakan Bengkel Gempur "A" bagi semua pelajar program Diploma Teknologi Maklumat (Teknologi Digital) bagi meningkatkan pencapaian pada peperiksaan akhir sesi Jun 2017.Selain itu, program ini juga merupakan salah satu usaha dalam memantapkan Continous Quality Improvement(CQI) berdasarkan dapatan pencapaian peperiksaan DBM2033 pada sesi Disember 2016 yang lepas. Walaubagaimanapun, persepsi pelajar terhadap bengkel ini masih belum dapat dipastikan sama ada ianya akan membantu atau tidak 
pencapaian pencapaian pelajar dalam kursus tersebut. Oleh itu, satu kajian perlu dijalankan bagi mendapatkan persepsi pelajar mengenai keberkesanan pelaksanaan bengkel ini.

\section{Objektif Kajian}

Tujuan kajian ini ialah untuk meninjau persepsi pelajar terhadap pelaksanaan Bengkel Gempur "A" untuk pelajar program Diploma Teknologi Maklumat(Teknologi Digital) di PSMZA.

\section{Skop Kajian}

Kajian ini dilaksanakan di Politeknik Sultan Mizan Zainal Abidin (PSMZA).Sampel bagi kajian ini ialah seramai 54 orang iaitu menggunapakai keseluruhan pelajar semester dua yang mengambil kursus DBM2033 bagi sesi Jun 2017. Kajian rintis juga telah dijalankan ke atas 15 orang pelajar dari kelas DDT2-S1.

\section{LITERATUR REVIEW}

\section{Persepsi}

Menurut Kamus Dewan Edisi Ketiga (2000), persepsi ditakrifkan sebagai gambaran atau bayangan dalam hati, fikiran mengenai sesuatu dan pandangan iaitu menerusi pancaindera atau tanggapan. Manakala Cambridge International Dictionary of English (1995) mendefinisikan perception (persepsi) sebagai "a belief or opinion, often held by many people on appearances" atau dalam Bahasa Melayu "suatu kepercayaan atau pendapat yang biasanya diberikan oleh orang ramai berdasarkan pemerhatian" (Derani, 2004). Fieldman (1999) menyatakan "Constructive process of perception that we go beyond the stimulus presented to us and try to build a meaningful situation." Persepsi merupakan sebuah proses konstruktif dimana seseorang itu berusaha untuk memahami situasi yang bermakna dan juga menerima stimulus (Fieldman, 1999). Sedangkan Morgan (1987) menyatakan "Perception refers to the mode of work, sound, feel, taste, or smell. In other works, perception can be defined as any experienced by someone" iaitu persepsi merujuk pada cara kerja, suara, rasa, selera, atau bau. Dengan kata lain, persepsi bolehditakrifkansebagai apa yang dialami oleh seseorang.

Pendapat lain diungkapkan oleh Thoha (2004), faktor-faktor yang mempengaruhi perkembangan persepsi seseorang adalah psikologi. Persepsi seseorang mengenai segala sesuatu di alam dunia ini sangat dipengaruhi oleh keadaan psikologi. Sebagai contoh,matahari yang terbenam pada waktu senja yang indah suasananya, ia dirasakan sebagai bayang-bayang yang kelabu bagi seorang yang buta warna. Faktor yang kedua ialah keluarga dan dalam konteks ini, mereka mempunyai pengaruh yang paling besar terhadap anak-anaknya. Banyak sikap dan persepsimereka yang diturunkan kepada anaknya terutama kepada ibu bapa yang telah mengembangkan suatu cara yang khusus iaitu dalam memahami dan melihat kenyataan di dunia ini.Contoh orang tua yang Muhammadiyah iaitu mempunyai sikap dan akhlak yang terpuji akanmempunyai anak- anak yang Muhammadiyah juga iaitu tinggi budi pekertinya. Seterusnya, persepsi juga turut dipengaruhi oleh kebudayaan. Salah satu faktor penting didalam mempengaruhi sikap, nilai, dan cara seseorang memandang dan memahami keadaan di dunia ini ialah kebudayaan dan lingkungan masyarakat tertentu. Sebagai contoh, Orang Amerika yang bebas makan daging babi, tidak begitu halnya bagi masyarakat Indonesia.

Persepsi dalam kajian ini merupakan persepsi pelajar terhadap Bengkel Gempur "A” bagi program Diploma Teknologi Maklumat (Teknologi Digital). Persepsi yang dimaksudkan termasuklah pandangan atau tanggapanpelajar terhadap fasiliti program, kandungan program, pengisian program, impak program atau pandangan peserta.Satu kajian yang bertajuk Student Perception of Learning Gains di Universiti Berkeley telah dilaksanakan oleh Gutwill (2000). Kajian mereka bertumpu kepada persepsi pelajar terhadap nilai tambah yang mereka perolehi semasa mengikuti kuliah dan aspek pedagogi juga turut dikaitkan melalui pengalaman pembelajaran di bilik kuliah (Kelly, 2000). Satu kajian juga telah dilakukan 
oleh Booth, Abdulla et.all (1998) tentang persepsi guru pelatih terhadap pembelajaran dan pengajaran.Kajian mereka yang bertajuk Student Teachers' Perceptions of Teaching and Learning Conditions in Fiji and Maldives dan hasil dapatan kajian telah dapat membantu persepsi guru pelatih terhadap suasana dan konteks pembelajaran yang berbeza di Fiji dan Maldives. Oleh yang demikian, dapatan data yang dikaji berdasarkan pandangan atau tanggapan pelajar dapat menyumbangkan nilai tambah terhadap pelaksanaan Bengkel Gempur "A" DDT.

\section{METODOLOGI}

\section{Rekabentuk Kajian}

Kajian ini berbentuk kajian kuantitatif dengan menggunakan pendekatan melalui borang soal selidik terhadap persepsi pelajar yang dihubungkait dengan keberkesanan pelaksanaan Bengkel Gempur "A" DDT. Kajian tinjauan merupakan salah satu kaedah penyelidikan yangpaling popular digunakan dalam pelbagai bidang khususnya dalam bidang sains sosial. Selain daripada bidang sains sosial, kaedah ini juga banyak dipraktikan dalam kajian yang melibatkan bidang pendidikan.Kaedah ini digunakan untuk mendapatkan maklumat daripada responden yang ramai melalui penentuan sampel daripada populasi. Menurut Mohammad Najib Abdul Ghafar (2003), sekumpulan masyarakat yang mempunyai ciri yang sama dikenali sebagai populasi. Manakala wakil atau contoh am populasi ialah sampel. Menurut beliau lagi, responden atau subjek ialah ahli sampel yang memberikan maklum balas. Menurut Azizi Yahya et al pula, (2007), satu set lengkap semua kumpulan merujuk kepada populasi dan dalam kajian ini ia merujuk kepada satu kumpulan manusia manakala sampel pula ialah sebahagian daripada populasi yang dipilih secara rawak. Sampel yang terpilih mestilah mempunyai ciri-ciri atau sifat-sifat populasi yang ingin dikaji supaya maklumat yang diperoleh melalui kajian berkenaan boleh memberi kenyataan dan gambaran umum tentang keseluruhan populasi yang dikaji.Justeru itu, kenyataan umum (generalization) tentang sesuatu populasi boleh dilakukan dengan menggunakan kaedah kajian tinjauan.

\section{Sampel Kajian}

Sampel kajian ini terdiri daripada pelajar semester dua, Diploma Teknologi Maklumat (Teknologi Digital), Politeknik Sultan Mizan Zainal Abidin bagi sesi Jun 2017 yang mengambil kursus DBM2033.Menurut Linacre (2005), bagi membentuk satu hasil kajian yang baik, sejumlah 30 responden sudah memadai untuk menunjukkan keputusan keyakinan yang sama walaupun jumlah sampel kajian yang berbeza. Pengkaji telah menggunakan keseluruhan populasi pelajar yang diambil sebagai sampel kajian kerana sampel memenuhi segala tuntutan, keperluan dan kehendak kajian.Selain itu, sampel menggambarkan populasi yang bertepatan dengan tuntutan tujuan kajian dan dapat menjawab persoalan kajian. Populasi bagi kajian ini ialah seramai 54 orang pelajar dan kesemuanya telah dipilih sebagai sampel kajian.Sampel kajian ini diambil dari kelas DDT2-S1 dan DDT2-S2 yang terdiri daripada 25 orang pelajar lelaki dan 29 orang pelajar perempuan.

\section{Instrumen Kajian}

Alat kajian adalah satu set soal selidik bagi meninjau persepsi pelajar semester dua yang mengambil kursus DBM2033 terhadap pelaksanaan Bengkel Gempur " A “ bagi Program Diploma Teknologi Maklumat (Teknologi Digital) PSMZA. Soal selidik ini mempunyai enam bahagian. Bahagian A mengandungi demografi pelajar seperti jantina, bangsa, umur, taraf pendidikan dan himpunan purata nilai mata (HPNM). Bahagian B pula mengandungi lima item soal selidik berkaitan fasiliti program, bahagian $\mathrm{C}$ terdiri daripada 12 item soal selidik berkaitan kandungan program, bahagian D mengandungi empat item soal selidik berkaitan pengisian program. Bahagian E pula mengandungi lima item soal selidik berkaitan keberkesanan ataupun impak manakala Bahagian F terdiri daripada tiga item soal selidik iaitu pandangan peserta. Kaedah statistik deskriptif digunakan dalam penganalisisan data yang berbentuk skala Likert (Empat Mata). 
Sebelum kajian sebenar dijalankan terlebih dahulu, penyelidik telah pun membuat membuat kajian rintis. Defini kajian rintis ialah kajian awal yang dijalankan sebelum menjalankan kajian sebenar. Menurut Mohd Najib Abd. Ghaffar (1999) sebelum kajian sebenar dijalankan, kajian rintis perlu dijalankan untuk mengetahui nilai kebolehpercayaan serta kesahan item- item soal selidik yang dibina. Bagi memastikan soal selidik yang diedarkan kepada sampel sebenar adalah berkualiti, penyelidik menjalankan kajian rintis ke atas 15 orang pelajar dari kelas DDT2-S1, PSMZA. Analisis daripada kajian dibuat dengan menggunakan ujian reliability pada program Statistical Package for The Social Sciences (SPSS) versi 23.0. Kebolehpercayaan item-item ditunjukkan oleh nilai alpha cronbach 0 hingga 1.0. Semakin besar nilai pekali sesuatu item, maka semakin tinggi darjah kebolehpercayaan item tersebut. Pekali kebolehpercayaan alpha cronbach pada keseluruhan 33 item ini ialah 0.930. Setelah kajian rintis dijalankan, penyelidik membuat beberapa perubahan dari sudut bahasa yang digunakan agar pelajar lebih mudah memahami soalan untuk kajian yang sebenar kelak.

Jadual 2:Pengkelasan Skala Likert (Empat Mata)

\begin{tabular}{|c|c|c|c|c|}
\hline & $\begin{array}{c}\text { Sangat Tidak } \\
\text { Setuju } \\
(1)\end{array}$ & $\begin{array}{c}\text { Tidak Setuju } \\
(2) \\
\end{array}$ & $\begin{array}{c}\text { Setuju } \\
\text { (3) } \\
\end{array}$ & $\begin{array}{c}\text { Sangat Setuju } \\
(4)\end{array}$ \\
\hline Kategori & \multicolumn{2}{|c|}{ Tidak Setuju } & \multicolumn{2}{|c|}{ Setuju } \\
\hline
\end{tabular}

\section{Pengumpulan Data}

Borang-borang soal selidik yang telah disesuaikan dengan keperluan kajian diserahkan kepada Ketua Jabatan Matematik, Sains dan Komputer untuk mendapatkan kebenaran kajian. Responden dikehendaki menjawab kesemua item dan seterusnya memberi pandangan mereka terhadap soal selidik tersebut. Kajian ini dijalankan dengan menggunakan kaedah tinjauan melalui soal selidik. Borang soal selidik diedarkan kepada pelajar di akhir sesi bengkel tersebut dan proses pengumpulan data soal selidik dilakukan sejurus selepas bengkel tersebut tamat. Soal selidik diberikan kepada 54 sampel terdiri daripada pelajar semester dua sesi Jun 2017 untuk meninjau persepsi pelajar terhadap pelaksanaan Bengkel Gempur "A".

\section{Analisis Data}

Penganalisaan data untuk kajian ini dilakukan dengan menggunakan Statistical Package for the Social Sciences (SPSS version 23.0). Skala likert digunakan untuk menganalisis soalan tertutup manakala statistik deskritif dan statistik inferensi digunakan untuk mentafsir soal selidik. Statistik deskritif ialah statistik yang digunakan untuk memerihalkan sesuatu peristiwa. Oleh itu, dalam kajian ini, peratusan telah digunakan untuk mengukur maklumat diri responden yang terdiri daripada jantina, bangsa, umur, taraf pendidikan dan himpunan purata nilai mata (HPNM). Manakala, statistik inferensi ialah cara bagaimana data digunakan untuk membuat anggaran, keputusan dan ramalan terhadap sesuatu perkara. Ujian analisis yang terlibat ialah ujian-t, ujian-t sampel-sampel padanan, dan analisis varian (ANOVA Satu Hala). Maka, sebelum melakukan analisis statistik inferensi, kaedah statistik berikut digunakan pada aras signifikan $\alpha=0.05$ atau pada tahap keyakinan $95 \%$ iaitu hipotesis sifar adalah ditolak. Ujian-t digunakan untuk menentukan perbezaan antara dua min bagi dua sampel bebas dan ujian-t sampelsampel padanan pula digunakan untuk membandingkan dua kumpulan berpasangan.Manakala, analisis varian (ANOVA Satu Hala) pula digunakan untuk menentukan perbezaan min bagi pemboleh ubah yang melebihi dua sampel bebas. 


\section{DAPATAN KAJIAN DAN PERBINCANGAN}

\section{Dapatan Deskritif}

Bahagian ini membincangkan mengenai latar belakang responden yang mengandungi 5 item berkaitan latar belakang responden. Aspek yang cuba dianalisis tertumpu kepada jantina, bangsa, umur, taraf pendidikan dan himpunan purata nilai mata (HPNM). Analisis data yang diperolehi dipersembahkan dalam bentuk peratusan supaya ia lebih mudah untuk difahami. Sampel kajian terdiri daripada 54 orang pelajar dari Jabatan Teknologi Maklumat dan Komunikasi di Politeknik Sultan Mizan Zainal Abidin. Daripada bilangan tersebut, bilangan responden perempuan adalah lebih besar berbanding responden lelaki iaitu seramai 29 orang (53.7\%) dan responden lelaki hanya terdiri daripada 25 orang (46.3\%) sahaja.

Jadual 3

Maklumat Demografi (Jantina)

\begin{tabular}{cc}
\hline Jantina & Peratus \\
\hline Lelaki & 46.3 \\
Perempuan & 53.7 \\
Jumlah & 100.0 \\
\hline
\end{tabular}

Terdapat 4 kategori bangsa responden iaitu Melayu, Cina, India dan lain-lain. Majoriti responden kajian adalah terdiri daripada bangsa Melayu iaitu seramai 37 orang atau $68.5 \%$ diikuti $14.8 \%$ (8 orang) responden yang berbangsa Cina. Manakala, hanya 9 responden (16.7\%) yang berbangsa India yang terlibat dalam kajian ini.

Jadual 5

Maklumat Demografi (Bangsa)

\begin{tabular}{cc}
\hline Bangsa & Peratus \\
\hline Melayu & 68.5 \\
Cina & 14.8 \\
India & 16.7 \\
Lain - lain & 0.0 \\
Jumlah & 100.0 \\
\hline
\end{tabular}

Terdapat dua kategori umur responden iaitu 18 hingga 20 tahun dan 21 hingga 23 tahun. Majorit responden kajian berumur di antara 18 hingga 20 tahun iaitu seramai 31 orang atau $57.4 \%$ diikuti $42.6 \%$ (23 orang) responden yang berumur 21 hingga 23 tahun.

Jadual6

Maklumat Demografi (Umur)

\begin{tabular}{cc}
\hline Umur & Peratus \\
\hline $18-20$ & 57.4 \\
$21-23$ & 42.6 \\
Jumlah & 100.0 \\
\hline
\end{tabular}

Kebanyakan responden kajian ini terdiri daripada pelajar yang mempunyai kelayakan akademik peringkat Sijil Pelajaran Malaysia (SPM) iaitu 27 orang (50.0\%) berbanding kelayakan akademik lain seperti STPM iaitu 10 orang (18.5\%) dan Sijil Kemahiran iaitu 17 orang (31.5\%). 
Jadual 7

Maklumat Demografi (Taraf Pendidikan)

\begin{tabular}{cc}
\hline Taraf Pendidikan & Peratus \\
\hline SPM & 50.0 \\
STPM & 18.5 \\
Sijil Kemahiran & 31.5 \\
Jumlah & 100.0 \\
\hline
\end{tabular}

Data yang dikaji juga menunjukkan perbezaan yang ketara dari aspek Himpunan Purata Nilai Mata (HPNM) responden. Majoriti responden mempunyai HPNM 2.50-2.99 (25 orang atau 46.3\%). Ini diikuti 19 orang responden $(35.2 \%)$ yang mempunyai HPNM 3.00-3.49, 6 orang $(11.1 \%)$ yang mempunyai HPNM 2.00-2.49 serta diikuti 4 orang (7.4\%) responden yang mempunyai HPNM 3.50-4.00.

Jadual 8

Maklumat Demografi (Himpunan Purata Nilai Mata)

\begin{tabular}{cc}
\hline HPNM & Peratus \\
\hline Di bawah 2.0 & 0.0 \\
$2.00-2.49$ & 11.1 \\
$2.50-2.99$ & 46.3 \\
$3.00-3.49$ & 35.2 \\
$3.50-4.00$ & 7.4 \\
Jumlah & 100.0 \\
\hline
\end{tabular}

\section{Dapatan Kajian}

Dapatan ini adalah bertujuan untuk menjawab objektifkajian yang telah dibina. Pembersihan data dilakukan terlebih dahulu untuk pembuangan data extreme bagi membolehkan data tertabur secara normal. Oleh itu, jadual tahap penilaian yang telah dibina oleh Ghani Hj Taib (1996) dijadikan panduan dalammenentukan tahap berdasarkan nilai skor min. Jadual 9 menerangkan interpretasi skor min empat skala.

Jadual 9

Jadual Interpretasi Skor Min Empat Skala

\begin{tabular}{|c|c|}
\hline Selang Skala Min & Interpretasi Tahap \\
\hline $1.00-2.00$ & Rendah \\
\hline $2.01-3.00$ & Sederhana \\
\hline $3.01-4.00$ & Tinggi \\
\hline
\end{tabular}

\section{Persepsi Pelajar Terhadap Bengkel Gempur "A"}

Antara tujuan kajian ini dijalankan adalah untuk melihat persepsi pelajar terhadap Bengkel Gempur "A". Berdasarkan Jadual 10, dilihat purata keseluruhan nilai skor min bagi aspek persepsi pelajar adalah tinggi iaitu 3.16. Ini menunjukkan tahap persepsi pelajar terhadap Bengkel Gempur " $A$ " berada pada tahap yang tinggi. Dapatan kajian menunjukkan bahawa item keberkesanan/impak program iaitu 3.48 merupakan min yang paling tinggi diperolehi dari kesemuabahagianmanakala Bahagian $\mathrm{F}$ iaitu pandangan peserta mencatatkan min terendah iaitu 2.34 namun begitu, ia masih berada pada tahap yang sederhana. Kesimpulannya, pelajar mempunyai persepsi yang tinggi terhadap Bengkel Gempur "A". 
Jadual 10

Persepsi Pelajar Terhadap Bengkel Gempur "A"

\begin{tabular}{ccc}
\hline Persepsi Pelajar & Sp & Min \\
\hline Bahagian B : Fasiliti Program & 0.65 & 3.47 \\
Bahagian C : Kandungan Program & 0.31 & 3.04 \\
Bahagian D : Pengisian Program & 0.55 & 3.45 \\
Bahagian E : Keberkesanan/Impak Program & 0.48 & 3.48 \\
Bahagian F : Pandangan Peserta & 0.46 & 2.34 \\
\hline
\end{tabular}

\section{Perbezaan Persepsi Dalam Kalangan Pelajar Berdasarkan Jantina}

Setelah menjalankan ujian-t, Jadual 11 menunjukkan tidak terdapat perbezaan yang signifikan terhadap persepsi secara statistik $(\mathrm{t}=.77 ; \mathrm{p}>.05)$ antara skor minresponden lelaki dengan skor min perempuan. Sehubungan dengan itu, tidak terdapat perbezaan persepsi dalam kalangan pelajar berdasarkan jantina.

Jadual 11

Perbezaan Persepsi Pelajar Dalam Kalangan Pelajar Berdasarkan Jantina

\begin{tabular}{ccccccc}
\hline Jantina & N & Min & Sp & Nilai t & Df & Sig. \\
\hline Lelaki & 25 & 3.20 & .45 & & & \\
Perempuan & 29 & 3.12 & .34 & .77 & 52 & .33 \\
\hline
\end{tabular}

Perbezaan Persepsi Dalam Kalangan Pelajar Berdasarkan Bangsa

Merujuk kepada Jadual 412, min persepsi dalam kalangan pelajar Diploma Teknologi Maklumat (Teknologi Digital) bagi bangsa Cina adalah yang paling tinggi iaitu 3.26 diikuti oleh bangsa Indiaadalah 3.25 dan bangsa Melayu iaitu 3.10.

Jadual 12

Statistik Deskriptif Perbezaan Persepi Dalam Kalangan Pelajar Berdasarkan Bangsa

\begin{tabular}{cccc}
\hline Taraf Pendidikan & N & Sp & Min \\
\hline Melayu & 37 & .37 & 3.10 \\
Cina & 8 & .53 & 3.26 \\
India & 9 & .30 & 3.25 \\
Lain - lain & - & - & - \\
Jumlah & 54 & .39 & 3.15 \\
\hline
\end{tabular}

Jadual 13

Ujian ANOVA Perbezaan Persepi Dalam Kalangan Pelajar Berdasarkan Bangsa

\begin{tabular}{cccccc}
\hline $\begin{array}{c}\text { Variabel Kuasa } \\
\text { Dua }\end{array}$ & $\begin{array}{c}\text { Jumlah Kuasa } \\
\text { Dua }\end{array}$ & dK & Min & F & p \\
\hline Antara Kumpulan & .24 & 2 & .12 & .77 & .47 \\
Dalam Kumpulan & 7.98 & 51 & .16 & & \\
Jumlah & 8.21 & 53 & & & \\
\hline
\end{tabular}

Ujian ANOVA sehala adalah tidak signifikan secara statistik $(\mathrm{F}(2,51)=.77$; $\mathrm{p}>.05)$. Ini menunjukkan tidak terdapat perbezaan min yang signifikan dan positif persepsi dalam kalangan pelajar berdasarkan bangsa.

\section{Perbezaan Persepsi Dalam Kalangan Pelajar Berdasarkan Umur}

Setelah menjalankan ujian-t, Jadual14 menunjukkan tidak terdapat perbezaan yang signifikan dan positif secara statistik $(\mathrm{t}=-.24 ; \mathrm{p}>.05)$ antara skor min peringkat umur. Sehubungan dengan itu, tidak terdapat perbezaan persepsi dalam kalangan pelajar berdasarkan umur. 
Jadual 14

Perbezaan Persepsi Pelajar Dalam Kalangan Pelajar Berdasarkan Umur

\begin{tabular}{ccccccc}
\hline Umur & $\mathbf{N}$ & Min & Sp & Nilai t & Df & Sig. \\
\hline $\begin{array}{c}18-20 \\
\text { tahun }\end{array}$ & 31 & 3.15 & .41 & & & 52 \\
$\begin{array}{c}21-23 \\
\text { tahun }\end{array}$ & 23 & 3.17 & .38 & -.24 & & .97 \\
\hline
\end{tabular}

Perbezaan Persepsi Dalam Kalangan Pelajar Berdasarkan Taraf Pendidikan

Berdasarkan Jadual15, min persepsi dalam kalangan pelajar Diploma Teknologi Maklumat (Teknologi Digital) bagi Sijil Pelajaran Malaysia (SPM) adalah yang paling tinggi iaitu 3.22 diikuti oleh taraf pendidikan bagi Sijil Kemahiran adalah 3.15 dan taraf pendidikan STPM iaitu 3.00.

Jadual 15

Statistik Deskriptif Perbezaan Persepi Dalam Kalangan Pelajar Berdasarkan Taraf Pendidikan

\begin{tabular}{cccc}
\hline Taraf Pendidikan & N & Sp & Min \\
\hline SPM & 27 & .36 & 3.22 \\
STPM & 10 & .54 & 3.00 \\
Sijil Kemahiran & 17 & .35 & 3.15 \\
(Kolej Komuniti/IKBN/ILP dan lain-lain) & & & \\
Jumlah & 54 & .39 & 3.16 \\
\hline
\end{tabular}

Jadual 16

Ujian ANOVA Perbezaan Persepi Dalam Kalangan Pelajar Berdasarkan Taraf Pendidikan

\begin{tabular}{cccccc}
\hline Variabel Kuasa Dua & $\begin{array}{c}\text { Jumlah Kuasa } \\
\text { Dua }\end{array}$ & dK & Min & F & p \\
\hline Antara Kumpulan & .34 & 2 & .17 & 1.11 & .34 \\
Dalam Kumpulan & 7.87 & 51 & .15 & & \\
Jumlah & 8.22 & 53 & & & \\
\hline
\end{tabular}

Ujian ANOVA sehala adalah tidak signifikan secara statistik $(\mathrm{F}(2,51)=1.11 ; \mathrm{p}>.05)$. Ini menunjukkan tidak terdapat perbezaan min yang signifikan dan positif persepsi dalam kalangan pelajar berdasarkan taraf pendidikan.

\section{Perbezaan Persepsi Dalam Kalangan Pelajar Berdasarkan Himpunan Purata Nilai Mata (HPNM)}

Berdasarkan Jadual17, min persepsi dalam kalangan pelajar berdasarkan HPNM bagi 3.00-3.49 adalah yang paling tinggi iaitu 3.28 diikuti oleh HPNM 2.00-2.49 adalah 3.16, HPNM 2.50-2.99 adalah 3.11 danHPNM 3.50-4.00 iaitu 2.87.

Jadual 17

Statistik Deskriptif Perbezaan Persepi Dalam Kalangan Pelajar Berdasarkan Himpunan Purata Nilai Mata (HPNM)

\begin{tabular}{llll}
\hline HPNM & N & Sp & Min \\
\hline Di bawah 2.0 & 0 & 0 & 0 \\
$2.00-2.49$ & 6 & .35 & 3.16 \\
$2.50-2.99$ & 25 & .38 & 3.11 \\
$3.00-3.49$ & 19 & .35 & 3.28 \\
$3.50-4.00$ & 4 & .66 & 2.87 \\
Jumlah & 54 & .39 & 3.16 \\
\hline
\end{tabular}




\begin{tabular}{cccccc}
\multicolumn{7}{c}{$\begin{array}{c}\text { Jadual 18 } \\
\text { Ujian ANOVA Perbezaan Persepi Dalam Kalangan Pelajar } \\
\text { Mata (HPNM) } \\
\text { Variabel Kuasa } \\
\text { Dua }\end{array}$} & $\begin{array}{c}\text { Jumlah Kuasa } \\
\text { Dua }\end{array}$ & dK & Min & F & p \\
\hline Antara Kumpulan & .67 & 3 & .22 & 1.47 & .23 \\
Dalam Kumpulan & 7.55 & 50 & .15 & \\
Jumlah & 8.22 & 53 & & \\
\hline
\end{tabular}

Ujian ANOVA sehala adalah tidak signifikan secara statistik $(\mathrm{F}(3,50)=1.47$; $\mathrm{p}>.05)$. Ini menunjukkan tidak terdapat perbezaan min yang signifikan dan positif persepsi dalam kalangan pelajar berdasarkan HPNM.

\section{Perbezaan Persepsi Dalam Kalangan Pelajar Berdasarkan Kandungan Program(Sebelum Dan Selepas)}

Setelah menjalankan ujian-t sampel-sampel padanan, Jadual 19 menunjukkan hasil analisis perbandingan purata (min) sebelum dan selepas menyertai Bengkel Gempur "A". Hasil daripada analisis menunjukkan bahawa skor min dan sisihan piawai sebelum program adalah 2.28 dan .56 manakala skor min dan sisihan piawai selepas menyertai program adalah 2.96 dan .19. Perbezaan skor min antara sebelum dan selepas menyertai program ialah -.69. Keputusan kajian adalah signifikan $(\mathrm{t}=-8.73$, $\mathrm{p}<.05)$. Terdapat perbezaan yang signifikan dan positif secara statistik antara skor min kandungan program. Ini menunjukkan bahawa persepsi pelajar terhadap pelaksanaan Bengkel Gempur "A" telah berubah selepas menyertai program ini.

Jadual 19

Perbezaan Persepsi Pelajar Dalam Kalangan Pelajar Berdasarkan Kandungan Program (Sebelum Dan Selepas)

\begin{tabular}{lllccccc}
\hline $\begin{array}{l}\text { Kandungan } \\
\text { Program }\end{array}$ & N & Min & Sp & Nilai t & Df & Sig. \\
\hline Sebelum & 54 & 2.28 & .56 & & & \\
Selepas & 54 & 2.96 & .19 & -8.73 & 53 & .00 \\
\hline
\end{tabular}

\section{Perbincangan}

Kajian ini dijalankan bagi meninjau persepsi pelajar terhadap pelaksanaan Bengkel Gempur "A" bagi Program Diploma Teknologi Maklumat (Teknologi Digital) PSMZA. Skor min pada tahap tinggi diperolehi bagi kesemua bahagian soalan kecuali pada Bahagian F iaitu pandangan peserta berada pada tahap yang sederhana. Ini menunjukkan tahap persepsi pelajar terhadap Bengkel Gempur " $A$ " berada pada tahap yang tinggi. Majoriti pelajar mempunyai persepsi yang positif dan dapatan ini disokong oleh kajian yang telah dijalankan oleh Robbins (2002). Hasil dapatan itu menyatakan bahawa persepsi positif merupakan penilaian individu terhadap suatu objek atau informasi dengan pandangan yang positif atau sesuai dengan yang diharapkan dari objek yang dipersepsikan atau dari aturan yang ada. Penyebab munculnya persepsi positif seseorang kerana adanya kepuasan individu terhadap objek yang menjadi sumber persepsinya, adanya pengetahuan individu, serta adanya pengalaman individu terhadap objek yang dipersepsikan.

Hasil dapatan kajian juga menunjukkan tidak terdapat perbezaan persepsi dalam kalangan pelajarberdasarkan faktor demografi responden iaitu jantina, bangsa, umur, taraf pendidikan dan himpunan purata nilai mata (HPNM). Jadi, dapat disimpulkan bahawa persepsi pelajar terhadap pelaksanaan Bengkel Gempur "A" tidak dipengaruhi oleh faktor demografi responden.Dapatan ini adalah bertentangan dengan dapatan kajianWan Kamarudin (2014) yang menyatakan bahawa perbezaan jantina 
juga mempengaruhi tahap pengetahuan, sikap, persepsi dan amalan responden. Sebagai contoh, pengetahuan aspek rohani antara lelaki dan perempuan adalah berbeza. Dalam hal ini, responden lelaki didapati lebih mendominasi berbanding dengan responden perempuan.Namun begitu, terdapat juga dapatan kajian yang lepas yang menyokong dapatan kajian ini iaitu menunjukkan tidak terdapat perbezaan signifikan persepsi berdasarkan faktor demografi. Sebagai contoh kajian yang telah dijalankan olehAhmad \& Tamuri(2010)menunjukkan bahawa faktor-faktor lain iaitu jantina, lokasi sekolah dan bidang pengkhususan guru tidak memberikan signifikan kepada persepsi mereka terhadap penggunaan BBM berasaskan TMm dalam kalangan guru-guru j-QAF.Kajian ini juga mendapati tidak terdapat perbezaan yang signifikan persepsi penggunaan BBM berasaskan TMm dalam kalangan guru berdasarkan jantina, lokasi sekolah dan bidang pengkhususan mereka.

Dapatan kajian bagi mengenalpasti persepsi dalam kalangan pelajar berdasarkan kandungan program (sebelum dan selepas menyertai program) menunjukkan bahawa keputusan kajian adalah signifikan iaitu terdapat perbezaan yang signifikan dan positif secara statistik antara skor min kandungan program. Ini menunjukkan bahawa persepsi pelajar terhadap pelaksanaan Bengkel Gempur " $A$ " telah berubah selepas menyertai program ini. Majoriti pelajar beranggapan bahawa kemahiran menyelesaikan masalah, kemahiran kerja berpasukan, kemahiran kritis, kemahiran kepimpinan, kemahiran komunikasi dan kemahiran pengurusan dapat dipertingkatkan setelah menyertai program ini. Ini menimbulkan persepsi yang positif di kalangan pelajar pada Bahagian $\mathrm{C}$ iaitu kandungan program. Dapatan ini disokong oleh kajianCh'ng (2017) iaitu dapat meningkatkan minat dan pencapaian peserta kajian untuk belajar selepas intervensi dijalankan. Isu keprihatinan yang pertama adalah peningkatan minat peserta kajian terhadap topik tersebut. Sebelum intervensi dijalankan, peserta kajian selalu tidak memberi perhatian, membuat kerja sendiri dan berkhayal dalam proses pembelajaran dan pengajaran Sains. Selepas intervensi dijalankan, pemahaman peserta kajian terhadap topik ini dapat menunjukkan peningkatan. Hal ini disokong dengan dapatan analisis soal selidik, temu bual, rekod anekdot, nota lapangan dan ujian kesan tindakan.

\section{KESIMPULAN}

Melalui dapatan kajian, skor min Bahagian $\mathrm{F}$ iaitu pandangan peserta berada pada tahap yang sederhana. Bagi memastikan Bengkel Gempur "A" ini mendapat impak yang lebih mendalam serta mendapat persepsi yang positif di kalangan pelajar, pengkaji mencadangkan agar penglibatan pelajar dalam program ini adalah secara sukarela. Pensyarah kursus seharusnya mengenal pasti pelajar yang tidak berminat untuk bergiat aktif dalam menyertai apa-apa program yang berkaitan dengan pembelajaran dan pengajaran. Pensyarah dan pihak terlibat perlu memberikan pendedahan atau motivasi kepada pelajar terbabit agar mereka sedar akan kepentingan menghadiri program seumpama ini. Antara halangan yang akan dihadapi ialah komitmen dari pelajar itu sendiri dalam menyiapkan diri untuk menyertai program berbentuk ilmiah seperti ini.Pelaksanaan Bengkel Gempur "A" ini dilakukan bagi memastikan pelajar mendapat keputusan yang baik dalam peperiksaan akhir bagi sesi Jun 2017. Melalui bengkel ini juga, pelajar juga akan didedahkan dengan teknik dan kaedah yang lebih mudah selain dari kaedah yang biasa dipelajari dari pensyarah kursus mereka.

Pengkaji perlu terlebih dahulu meyakinkan responden bahawa semua maklumat adalah rahsia dan diproses secara berkumpulan untuk tujuan statistik. Pengkaji akan datang perlu mendapatkan persetujuan dan kerjasama dari ketua jabatan untuk mengumpulkan sebilangan responden dalam satu masa dan memberikan penerangan yang jelas tentang tujuan kajian serta memperuntukkan masa tertentu untuk responden menjawab soalan. Maka, ia dapat mengelakkan keraguan di kalangan responden dan penyelidik berpeluang menerangkan tujuan kajian terlebih dahulu.Sampel responden yang melibatkan beberapa buah politeknik seharusnya digunapakai bagi memastikan keputusan kajian yang lebih tepat dan jitu.Kaedah pengumpulan data juga perlu dipelbagaikan dan tidak hanya fokus kepada kaedah menggunakan soal selidik sahaja. Selain dari kaedah tersebut, kaedah temuduga dan pemerhatian juga boleh dijalankan. 
Rumusan dari Course Review Report (CORR) keputusan Peperiksaan Akhir sesi Dis 2016 di PSMZA mendapati pencapaian pelajar dalam DBM2033 adalah sederhana iaitu sekitar $61 \%$. Kesinambungan dari itu, satu bengkel iaitu Bengkel Gempur "A" bagi program Diploma Teknologi Maklumat (Teknologi Digital) telah diadakan bagi memulihkan dan meningkatkan prestasi pelajaragar dapat menghasilkan keputusan yang lebih baik pada peperiksaan akhir sesi Jun 2017. Kajian ini bertujuan untuk meninjau persepsi pelajar terhadap pelaksanaan Bengkel Gempur "A" bagi Program DDT di PSMZA. Kajian ini melibatkan pelajar semester dua bagi sesi Jun 2017 yang mengambil kursus Discrete Mathematics (DBM2033). Hasil dari dapatan kajian ini menunjukkan tahap persepsi pelajar terhadap Bengkel Gempur "A" berada pada tahap yang tinggi dan pelajar mempunyai persepsi yang positif setelah mengikuti bengkel ini. Walaubagaimanapun, dapatan kajian menunjukkan tidak terdapat perbezaan persepsi dalam kalangan pelajar berdasarkan faktor demografi responden iaitu jantina, bangsa, umur, taraf pendidikan dan himpunan purata nilai mata (HPNM). Jadi, dapat disimpulkan bahawa persepsi pelajar terhadap pelaksanaan Bengkel Gempur "A" tidak dipengaruhi oleh faktor demografi responden.

Persepsi pelajar terhadap pelaksanaan Bengkel Gempur "A" telah berubah selepas menyertai program ini. Majoriti pelajar beranggapan bahawa kemahiran menyelesaikan masalah, kemahiran kerja berpasukan, kemahiran kritis, kemahiran kepimpinan, kemahiran komunikasi dan kemahiran pengurusan dapat dipertingkatkan setelah menyertai program ini. Hal ini telah dibuktikan melalui skor min sebelum program adalah 2.28 dan skor min selepas menyertai program ini adalah 2.96 iaitu meningkat sebanyak 0.68. Penyelidik mendapati bahawa kajian ini telah berjaya mencapai objektifnya iaitu meninjau persepsi pelajar terhadap pelaksanaan Bengkel Gempur "A" bagi program DDT di PSMZA. Bagi memastikan kecemerlangan pelajar dalam kursus ini, penyelidik mencadangkan agar Bengkel Gempur " $A$ " atau program seumpama ini diteruskan pada setiap semester supaya pelajar dapat menimba lebih banyak ilmu serta diberikan pendedahan dan teknik-teknik mudah berkaitan dengan topik yang dipelajari. Penyelidik juga mencadangkan agar fasiliti program iaitu dari segi suasana tempat program mestilah berada dalam keadaan yang kondusif dan juga masa yang diperuntukkan untuk berbengkel mestilah bersesuaian iaitu tidak terhad kepada sehari sahaja. Secara kesimpulannya, lebih banyak kajian seperti ini dijalankan supaya masalah pelajar terutamanya berkaitan pembelajaran dan pengajaran dapat diselesaikan. Sampel responden yang melibatkan beberapa buah politeknik seharusnya digunapakai bagi memastikan keputusan kajian yang lebih tepat dan jitu. Bengkel Gempur "A" terbukti berkesan dalam meningkatkan prestasi pelajar dan persepsi pelajar telah berubah setelah mengikuti program ini.

\section{DAFTAR PUSTAKA}

Abu Bakar, Z., \& Ismail, N. H. A. (2011). Persepsi Dan Sikap Pelajar Terhadap. Persepsi Dan Sikap Pelajar Terhadap Pendekatan Konstruktivisme Serta Kesan Terhadap Pencapaian Dalam Mata Pelajaran Matematik Di Fakulti Pendidikan Universiti Teknologi Malaysia Zainudin, 3(December 2010), 2-9.

Ahmad, S. F., \& Tamuri, A. H. (2010). Persepsi Guru Terhadap Penggunaan Bahan Bantu Mengajar Berasaskan Teknologi Multimedia dalam Pengajaran j-QAF. Journal of Islamic and Arabic Education, 2(2), 53-64.

Azizi Yahaya, Shahrin Hashim, Jamaludin Ramli, Yusof Boon \& Abdul Rahman (2007). Menguasai penyelidikan dalam pendidikan. Universiti Teknologi Malaysia: PTS Profesional.

Ch'ng, L. K. (2017). No Title. Kesan Aktiviti Hands-On Terhadap Minat Dan Pencapaian Murid Tahun Empat Dalam Topik Sifat Bahan Di Kuching, 19. Retrieved from http://www.ipbl.edu.my/portal/penyelidikan/BukuKoleksi/2017/SN/CH\%27NG LEE KHENG/ARTIKEL_KAJIAN_TINDAKAN.pdf $\$

Cohen, L.., Manion, L.., \& Morrison, K. (2011). Research Methods In Education (7th ed,. Vol. 55). New York: Routledge. http://doi.org/10.1111/j.1467-8527.2007.00388_4.x

Derani, R. (2004). Persepsi Ibu Bapa Terhadap Faktor-Faktor Keruntuhan Akhlak Remaja Islam Masa Kini:

Satu

TinjauanDiTamanAmanAnakBukit,AlorSetarKedah.,131.Retrievedfromhttp://www.fp.utm.my/ep usatsumber/pdffail/ptkghdfwp2/p_2004_5758_5524fd02a33545bb98e6b186be8904e7.pdf 
Gardiner, W.L. (1989). Forecasting, Planning anf the future ofinformation society. Dlm. High technology workplace:Integrating technology, management and design for productive work environments, Goumain, P. $\quad$ (Ed.). 27-39.New York: Van Nostand Reinhold

Ghani Hj Talib, (1996). Pembinaan Instrumen: Ceramah Kursus Penyelidikan Pendidikan, Anjuran Bahagian Pendidikan Guru, Kementerian Pendidikan Malaysia, 12-13 Ogos 1996.

Kelly, Rob Roy.(2000) Students Teachers.http://www.rit.edu/ rkelly/html/03_ped/ped_stu1.html

Linacre, J. M. (1994). Sample size and item calibration stability. Rasch Measurement Transactions, 7, 328.

Mohammad, S. H., \& Mohd Roslan, N. S. (2017). Tahap Kebimbangan Matematik Dan Hubungannya Dengan Pencapaian Pelajar Di Politeknik Muadzam Shah, Pahang. TAHAP KEBIMBANGAN MATEMATIK DAN HUBUNGANNYA DENGAN PENCAPAIAN PELAJAR DI POLITEKNIK MUADZAM SHAH, PAHANG, 11.Retrievedfromhttp://www.fp.utm.my/epusatsumber/pdffail/ptkghdfwp2/p_2006_6741_8745383 5a596431a89bd14c15a724c5e.pdf

Mohd. Najib Abdul Ghafar (2003). Rekabentuk tinjauan soal selidik pendidikan. Johor Bahru: UMIDAINDUSTRIES Sdn.Bhd

Mohd. Najib Abd Ghaffar (1999). Penyelidikan pendidikan. Skudai: Penerbit Akademik Universiti Teknologi Malaysia.

Nasrah Binti Said (2012). Tahap Kepimpinan Instruksional Dalam Kalangan Pensyarah Politeknik Di Negeri Terengganu. Universiti Utara Malaaysia

Norziah Othman, Effandi Zakaria \&Zanaton Iksan. (2014).Nilai Dalam Pengajaran Matematik Di Institusi Pengajian Tinggi. e-Jurnal Penyelidikan dan Inovasi KUIS Jilid 1(II): 56-68.

Office of Institutional Effectiveness \& Analysis, Florida Atlantic University.(2002).Student Perception of Teaching. http://www.fau.edu/projects/spot/instructor.php 9

Renga, S., \& Dalla, L. (1993). Affect: A critical component of mathematical learning in early childhood. In R.J. Jensen (Ed.). Research ideas for the classroom: Early childhood mathematics (pp. 22-39).New York: Macmillan.

Scarpello, G. (2007). Helping Students Get Past Mathematics Anxiety, Connecting education and careers, 82(6), 34-35

Seymour, Elaine dan Gutwill, Joshua. (2000), "Student Perception ofLearning Gain”http://newtraditions.chem.wisc.edu/Flag/pages/Complete/ProcessTools/MC2Gain s_srvy.htm - Top

Wan Kamarudin, W. A. Z. (2014). Volume 3 Issue 12014 Academia Journal UiTMT (http://journaleacademiauitmt.edu.my/) 62, 3(1), 62-67. $\quad$ Retrieved from http://journaleacademiauitmt.uitm.edu.my/v2/images/vol4issue12015/Article_03_Volume_4_Issue 1_2015.pdf

Zeynivandnezhad, F., Ismail, Z., \& Yusof, Y. M. (2012). Mathematics Requirements for Vocational and Technical Education in Iran. Procedia - Social and Behavioral Sciences, 56(Ictlhe), 410415.https://doi.org/10.1016/j.sbspro.2012.09.670 